Differential- und Integralrechnung. Erster Band: Differentialrechnung. By Fr. W. Meyer. Second edition. Berlin and Leipzig, G. J. Göschen, 1912 (Sammlung Schubert, X). $\mathrm{xv}+418 \mathrm{pp}$.

THE first edition of this book was published in 1901. In the present edition a large number of details are altered, but the general development is the same as in the earlier one. Thus, old Art. 12 is now pushed into the first chapter and made Art. 6. The new Art. 15 is much shortened. Maxima and minima of functions of more than one variable are introduced. An appendix is provided which treats of tangents and normals.

VIRGIL SNYDER.

\title{
NOTE ON “THE DISCOVERY OF INVERSION.”
}

IN a review* under this title of Professor Bützberger's monograph, Ueber bizentrische Polygone, etc., I referred to a theorem on generalized Steinerian series of circles, which I proved in 1901 in connection with an application of elliptic functions to certain closed linkages.

Since the appearance of this review my attention has been drawn to the fact that A. Hurwitz had previously stated the main part of the theorem in an article, Ueber die Anwendung der elliptischen Funktionen auf Probleme der Geometrie, which appeared in the Mathematische Annalen, volume 19, page 65.

As will be noticed, Hurwitz, without proof, merely states the theorem, and his method by which it can be proved is entirely different from that of closed linkages.

This note also applies to a similar statement concerning the same theorem in the "Sprechsaal† für die Encyklopädie der mathematischen Wissenschaften."

ArNold EMch.

\section{CORRECTION.}

Professor Veblen has kindly called my attention to an error in my review of "Monographs on Topics of Modern Mathematics" in the Bulletin for January, 1914. The

* Bulletin, vol. 20, p. 413.

$\dagger$ Jahresbericht d. Deutschen Mathematiker-Vereinigung, vol. 23, 2. Abt., Heft 3/4, pp. 50-51. 